\title{
RESEARCH
}

\section{THE ROLE OF FRAILTY IN PHYSICIANS' DECISIONS FOR SEVERE DISABILITY}

Turkish Journal of Geriatrics

DOI: 10.31086/tigeri.2020.187

2020; 23(4): 492-500

\section{- Cemile HAKi ${ }^{1}$ D \\ - Hakan DEMiRCi2}

CORRESPONDANCE

\section{${ }^{1}$ Cemile HAKI}

Bursa Yuksek Ihtisas Training and Research Hospital, Department of Neurology, Bursa, Turkey

Phone: +905324713151

e-mail: cemilehaki@gmail.com

Received: Jun 17, 2020

Accepted: Nov 12, 2020

1 Bursa Yuksek lhtisas Training and Research

Hospital, Department of Neurology, Bursa,

Turkey

2 Bursa Yuksek Ihtisas Training and Research Hospital, Department of Family Medicine, Bursa, Turkey

\section{A}

Introduction: We aimed to evaluate the correlation between disability approved by the medical board and frailty determined by the Edmonton Frail Scale, which is a tool used to assess frailty.

Materials and Method: We enrolled patients admitted to the neurology outpatient clinic of the Bursa Yuksek Ihtisas Training and Research Hospital between 1st-31st March 2019 for examination in order to obtain a disability report from the medical board.

Results: Cerebrovascular disease and dementia were more prevalent in older age, while epilepsy, cerebral palsy sequela and other neurological diseases were observed at a younger age. A strong correlation was observed between frailty analysis score and Balthazard disability percentage $(p<0,001, r=0,57)$. Similarly, there was a correlation between the physicians' severe disability opinion and the Edmonton Frail index score. Scores for cognition, general health status, functional independence, frequency of forgetting to take prescription drugs, or indications of recent weight loss were higher for patients in the severe disability group who also had higher EFS scores. We found that EFS scores $>8$ correlate significantly with an increased risk of severe disability.

Conclusion: We conclude that use of the frailty analysis score in combination with Balthazard disability percentage for patients applying to the medical board could be practical and rational in evaluating the degree of disability and predicting severe disability. Since only patients who applied for medical board evaluation to the neurology clinic were included in our study, our results are relevant for neurology cases and cannot be generalized for all patients who applied for evaluation.

Keywords: Frailty; Social Support; Disability Evaluation; Frail Elderly; Cerebrovascular Disorders 


\section{INTRODUCTION}

A disabled person is defined as an "individual affected by environmental aspects and attitudes restricting his/her total and effective integration in society in equal conditions with other individuals due to various levels of loss in his/her physical, mental, spiritual and sensorial abilities" (1).

The "World Report on Disability," published in 2011 , stated that $15.6 \%$ of the world's adult population (aged 18 and over) suffer from a disability. According to the "Turkey Disabled Research 2002" report, conducted by the Prime Ministry's State Institute of Statistics and the Prime Ministry Department for the Administration of the Disable, found that $12.29 \%$ of the Turkish population had some form of disability $(2,3)$.

Living standards for disabled citizens and the quality of service provided to these individuals are two important indicators of a country's level of development. In Turkey, disabled persons can be admitted to a health care provider who is authorized to certify an annual disability report, which allows that individual to request a medical board report that is needed for claiming social benefits such as financial support, disability allowance, employment, education, disability retirement, and tax reductions. Those who receive medical board approval are evaluated by specialists in physical medicine and rehabilitation, internal medicine, ophthalmology, otorhinolaryngology, general surgery, neurology, and mental health, and their disability status is graded using the percentage scale (from zero to 100), according to disability rates tables. These regulations categorize individuals who are unable to fulfil their daily needs even if they receive help as severely disabled (or "fully dependent disabled") (1). Patients who are considered severely disabled ("fully dependent disability") are presented to the physicians on the committee.

Frailty is defined as a state of increased vulnerability to stress factors as a result of age-related decreases in physiological abilities (4). As frailty levels

Table 1. Distribution of chronic diseases by gender

\begin{tabular}{|c|c|c|c|}
\hline Chronic Disease & $\begin{array}{c}\text { Female } \\
(n=44)\end{array}$ & $\begin{array}{c}\text { Male } \\
(n=46)\end{array}$ & p-value \\
\hline Cerebrovascular Disease & $18(40.90 \%)$ & $15(32.60 \%)$ & $0.414^{a}$ \\
\hline Epilepsy & $5(11.40 \%)$ & $9(19.60 \%)$ & $0.283^{a}$ \\
\hline Dementia & $12(27.30 \%)$ & $6(13 \%)$ & $0.092^{\mathrm{a}}$ \\
\hline Parkinson Disease & $1(2.30 \%)$ & $1(2.20 \%)$ & $1.00^{\mathrm{b}}$ \\
\hline Cerebral Palsy Sequel & $2(4.50 \%)$ & $2(4.30 \%)$ & $1.00^{\mathrm{b}}$ \\
\hline Other Neurologic Disease & $11(25 \%)$ & $14(30.40 \%)$ & $0.565^{\mathrm{a}}$ \\
\hline Neuropathic Pain & $5(11.40 \%)$ & $7(15.20 \%)$ & $0.591^{\mathrm{a}}$ \\
\hline Hypertension & $10(22.70 \%)$ & $14(30.40 \%)$ & $0.408^{a}$ \\
\hline Diabetes Mellitus & $8(18.20 \%)$ & $9(19.60 \%)$ & $0.867^{a}$ \\
\hline Cardiac Disease & $8(18.20 \%)$ & $11(23.90 \%)$ & $0.505^{a}$ \\
\hline Orthopedic Diseases & $2(4.50 \%)$ & $1(2.20 \%)$ & $0.612^{b}$ \\
\hline Eye Diseases & $3(6.80 \%)$ & $1(2.20 \%)$ & $0.355^{b}$ \\
\hline Psychiatric Diseases & $5(11.40 \%)$ & $4(8.70 \%)$ & $0.737^{b}$ \\
\hline Other Diseases & 18(40.90\%) & $15(32.60 \%)$ & $0.414^{\mathrm{a}}$ \\
\hline
\end{tabular}

Data expressed asn (\%), a: Pearson chi-square test, b: Fisher'sexactchi-square test

Note: More than one disease may occur in the same patient. 
Table 2. Chronic disease and age correlation

\begin{tabular}{|c|c|c|c|c|}
\hline Chronic Disease & $\begin{array}{l}\mathrm{n} \text { with the disease/ } \\
\text { free from the disease }\end{array}$ & Positive & Negative & p-value ${ }^{c}$ \\
\hline CVD & $33 / 57$ & 68(44-89) & $58(22-90)$ & 0.003 \\
\hline Epilepsy & $14 / 76$ & $40(22-78)$ & $65(24-90)$ & $<0.001$ \\
\hline Dementia & $18 / 72$ & $83(37-90)$ & $58.50(22-89)$ & $<0.001$ \\
\hline Parkinson Disease & $2 * / 88$ & $60.50(37-84)$ & $63(22-90)$ & NA \\
\hline Cerebral Palsy Sequel & $4 / 86$ & $31.50(22-37)$ & $63.50(24-90)$ & $<0.001$ \\
\hline Other Neurologic Diseases & 25/65) & $52(24-84)$ & $66(22-90)$ & 0.002 \\
\hline Neuropathic Pain & $12 / 78$ & $59(31-70)$ & $64(22-90)$ & 0.288 \\
\hline Hypertension & $24 / 66$ & $65(42-88)$ & $62(22-90)$ & 0.273 \\
\hline Diabetes Mellitus & $17 / 73$ & $63(48-84)$ & $63(22-90)$ & 0.351 \\
\hline Cardiac Disease & $19 / 71$ & $66(58-89)$ & $59(22-90)$ & 0.011 \\
\hline Orthopedic Diseases & $3 * / 87$ & $65(58-81)$ & $63(22-90)$ & NA \\
\hline Eye Diseases & $4 / 86$ & $73(36-84)$ & $62.50(22-90)$ & 0.478 \\
\hline Psychiatric Diseases & $9 / 81$ & $46(37-83)$ & $63(22-90)$ & 0.208 \\
\hline Other Diseases & $33 / 57$ & $62(24-90)$ & $63(22-89)$ & 0.947 \\
\hline
\end{tabular}

For each chronic disease the data in the upper row is median age (minimum -maximum), $\mathrm{n}$ is the number of subjects having the disease /free from the disease.

*: Unit number in the group not enough for statistical analysis. c: Mann Whitney $U$ test

Note: More than one disease may occur in the same patient.

increase with more exposure to stress factors, so too does the risk of hospitalization, falls, delirium, mortality, and morbidity $(5,6)$. Frailty has become a more pressing issue as the world population continues to age, with levels of frailty between 4 and $59.1 \%$ having been reported (7). The prevalence of frailty among patients admitted to outpatient clinics in developing countries is particularly high, at 55 to $71 \%$ in Brazil and $28 \%$ in Peru (8). In Turkey, this rate is $39.2 \%(9)$.

There is no existing literature that applies the Edmonton Frail Scale (EFS) — which is used to assess frailty - to patients who are admitted to a medical board for disability evaluation in order to determine whether frailty levels can be used to predict approved disability status. The aim of this study is to evaluate the correlation between disability approval by a medical board in Turkey and frailty as detected by the EFS.

\section{METHODS}

Patients with a neurological disability who applied to the institutional health board of Bursa Yuksek Ihtisas Training and Research Hospital for the purpose of obtaining a disability report between the 1 st and 31st March 2019, and had been admitted to the neurology outpatient clinic for examination, were included in the study. Patients under the age of 18, those who applied to obtain a medical committee report for job application, driver's license, gun license, rest report and status reports were excluded from the study.

For each patient, we recorded age, gender, diagnosis, comorbidity, disability rates, and severe disability status. Patients were also evaluated using the EFS. The patients' disability statuses, which were being presented to the medical board for evaluation, were calculated using the Balthazard formula, after they had been assessed by specialists from each of the divisions listed above. The Baltha- 
Table 3. Relationship between Balthazard Disability Percentage and Edmonton Frail score

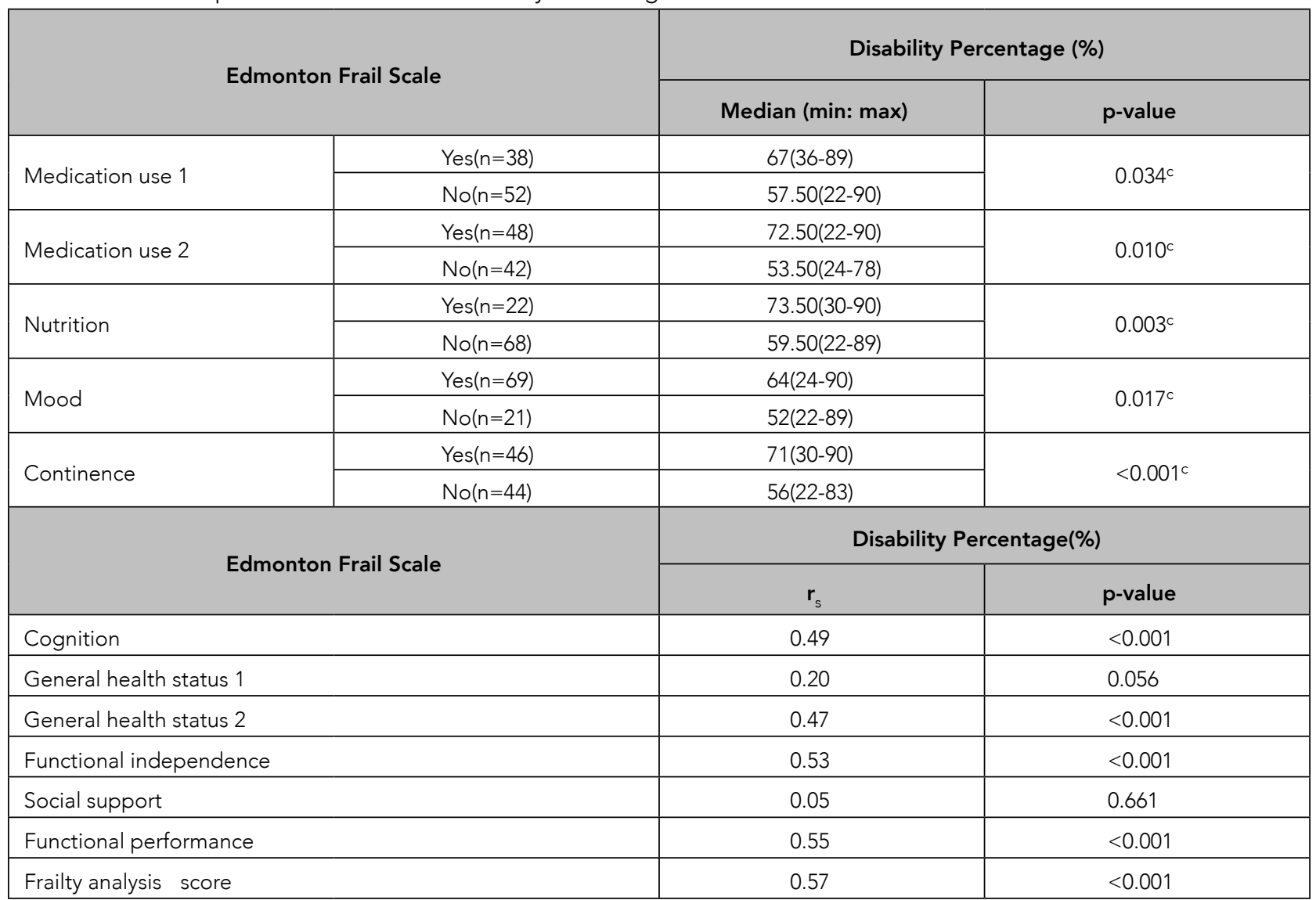

Data is given as median(minimum: maximum). c: Mann Whitney $\mathrm{U}$ test

$r_{s}$ : Spearman correlation coefficient

Medication use 1: Do you regularly use 5 or more different drugs?

Medication use 2: Do you forget to take your prescription medicines from time to time?

General Health 1: How many times were you hospitalized last year?

General Health 2: How would you describe your health in general?

zard formula is used to calculate degree of impairment for individuals with more than one disability (1). The EFS is a simple test that was developed by Rolfson et al. at the University of Alberta in Canada, consisting of 11 questions and a physical assessment (10). Turkish validity and reliability studies for the EFS were conducted by Aygor et al. (11). Our scale for this study consisted of 11 questions covering nine items: cognitive status, general health status, functional independency, social support, med- ication usage, nutrition, mood, continence, and functional performance. All items were assessed with one question, except general health status and medication usage, which used two questions. Cognitive status and functional performance were tested using the EFS; the timed-up-and-go test (TUGT) was used to assess functional performance; and the clock-drawing test was used to assess cognitive status (10). The EFS test is scored between 0-17, with the following categories: 0-4 - not frail; 5-8 - vulner- 
Table 4. Relationship between frailty total and sub-group scores and severe disability status

\begin{tabular}{|l|c|c|c|}
\hline \multirow{2}{*}{$\begin{array}{c}\text { Edmonton } \\
\text { Frail Scale }\end{array}$} & Yes (n=33) & Novere Disability $(\mathbf{n}=57)$ & p-value \\
\cline { 2 - 4 } & $2(0-2)$ & $1(0-2)$ & $<0.001^{c}$ \\
\hline Cognition & $0(0-1)$ & $0(0-2)$ & $0.088^{c}$ \\
\hline General Health 1 & $2(1-2)$ & $1(1-2)$ & $<0.001^{c}$ \\
\hline General Health 2 & $2(1-2)$ & $1(0-2)$ & $<0.001^{c}$ \\
\hline Functional independence & $0(0-2)$ & $0(0-2)$ & $0.314^{c}$ \\
\hline Social support & $15(45.50 \%)$ & $23(40.40 \%)$ & $0.637^{\mathrm{a}}$ \\
\hline Medication use 1 & $25(75.80 \%)$ & $23(40.40 \%)$ & $0.001^{\mathrm{a}}$ \\
\hline Medication use 2 & $14(42.40 \%)$ & $8(14 \%)$ & $0.003^{\mathrm{a}}$ \\
\hline Nutrition & $27(81.80 \%)$ & $42(73.70 \%)$ & $0.379^{\mathrm{a}}$ \\
\hline Mood & $28(84.80 \%)$ & $18(31.60 \%)$ & $<0.001^{\mathrm{a}}$ \\
\hline Continence & $2(0-2)$ & $0(0-2)$ & $<0.001^{\mathrm{c}}$ \\
\hline Functional performance & $11(5-14)$ & $6(1-13)$ & $<0.001^{\mathrm{c}}$ \\
\hline Frailty Score & & & \\
\hline
\end{tabular}

Data given as median (minimum: maximum) and $n(\%)$.

a: Pearson chi-square test, c: Mann Whitney $U$ test

able; 7-8 - mild frailty; 9-10 - moderate frailty; and 11 and above - severe Frailty.

Assessment of disability rates for all patients were conducted as per the guidelines in the "Regulation on Disability Assessment for Adults," published in Official Gazette No.30692 on February 20, 2019. Approval for the study was received from the Bursa Yuksek Ihtisas Training and Research Hospital Ethics Committee (2011-KAEK-25 2019/02-21).

\section{Statistical analysis}

Based on the findings of this study, we conducted a post hoc power analysis using a large effect size, which was calculated by comparing the average EFS scores between severe disability status groups. Using an effect size of $(d=1.56)$ with a sample size of 90 $\left(n_{1}=57, n_{2}=33\right)$, we achieved an estimated power of $95 \%$ with a significance level of $\alpha=0.05$. A Kolmogorov-Smirnov test was used to assess whether the variables followed a normal distribution. Variables were reported as median (minimum: maximum) values. Based on the normality test results, a Mann Whitney $U$ test was used to perform between-group comparisons. Categorical variables were compared using a Chi-square test or a Fisher's exact test. In order to estimate the sensitivity and specificity of EFS score values in predicting severe disability status, a receiver operator characteristic (ROC) curve analysis was performed. The reliability of the EFS was assessed using Cronbach's alpha $(\alpha)$ coefficient; the reliability of the EFS was determined as $\alpha=0.83$. We used SPSS (IBM Corp., released 2015. IBM SPSS Statistics for Windows, Version 23.0. Armonk, NY) and MedCalc Statistical Software, trial version 16.4.3 (MedCalc Software bvba, Ostend, Belgium; https://www.medcalc.org; 2016) were used. A p-value of $<0.05$ was considered statistically significant.

\section{RESULTS}

Ninety people participated in the study. A total of 44 (48.8\%) participants were female and 46 (51.1\%) were male. The mean age of the participants was $60.5 \pm 18.3$ (min-max: 22-90) years. The median Edmonton Frail Scale (EFS) score was 9 (1-14). The median disability rate of the whole group was $87.5 \%$ 
Figure 1. Receiver-operator characteristic $(R O C)$ curves for determining the presence of severe disability. The area under the curve (AUC) for Edmonton Frail Scale Score is 0.84 with $p<0.001$.



(26-100\%). In our study, cerebrovascular diseases (36.6\%), dementia (20\%), and epilepsy (15.5\%) were among the most frequent causes of neurological disability. No statistical difference was observed between genders for cerebrovascular disease, epilepsy, or Parkinson's disease patients. Although dementia was more common among women, no statistically significant difference was observed ( $p>0.05)$. Distribution of chronic diseases by gender is shown in Table 1.

Table 2 shows that the median age for those with cerebrovascular disease or dementia was higher. Epilepsy was more common in younger participants, but cerebral palsy patients were on average the youngest. Correlation between chronic diseases and age are shown in Table 2.

Disability percentages were higher for patients who regularly used five or more different medications, as well as for those who forgot to take their prescription drugs, those who indicated that they had lost weight recently, those who frequently felt upset or depressed, and those who suffered from involuntary urination. An increase in disability percentages was detected in patients who had higher scores for cognition, general health status (based on the question, "In general, how would you describe your health?"), and functional independence. A significant parallel correlation was found between disability percentages and EFS score. The relationship between the Balthazard disability percentages and EFS scores is shown in Table 3.

Scores for cognition, general health status, functional independence, rates of forgetting to take prescription drugs, or indications of recent weight loss were higher for patients in the severe disability group; EFS scores were also higher for this group. The correlations between EFS scores and committee-certified disability status certified are included in Table 4.

A ROC curve analysis was performed to estimate the sensitivity and specificity of EFS scores in predicting the presence of severe disability, with a 
cut-off point for EFS scores being set at $>8$ (see Figure 1). The area under the curve for the EFS score was 0.84 (sensitivity: 93.90\%; specificity: 66.70\%; $\mathrm{p}<0.001$ ), indicating that EFS scores $>8$ correlate significantly with an increased risk of severe disability.

\section{DISCUSSION}

The power of the research was calculated as $95 \%$. While cerebrovascular disease and dementia were more common in older participants, epilepsy, cerebral palsy, and other neurological diseases were observed in younger patients. A strong correlation was observed between EFS score and Balthazard disability percentage; there was also a correlation between physicians rating a patient as severely disabled and EFS index score.

There are not many studies on neurological disability in our country. One of the few, conducted by Çabalar et al. (12), reported that $10.87 \%$ of patients admitted to a medical board for evaluation were judged to be disabled because of their suffering from a neurological disease. another study by Benli Ar et al. (13) reported a figure of $22.3 \%$ for the same class of patients.

According to this research by Çabalar et al. (12), the highest mean age of any group admitted to the medical board with neurological disorders was for the group of dementia and Parkinson's disease patients. In our study, the highest mean age was for dementia patients, while the second highest was for cerebrovascular disease. Epilepsy was more common for younger patients, while the youngest admitted patients were those with cerebral palsy. The diseases that most often caused neurological disability were cerebrovascular diseases, dementia, and epilepsy, according to the studies by Çabalar et al. (12) and Evlice et al. (14). Similarly, we observed that the most common neurological diseases among patients admitted to the medical evaluation board were cerebrovascular diseases, dementia, and epilepsy.
Çabalar et al. (12) found that $56.2 \%$ of the neurologically disabled patients admitted to the medical board were male and $43.8 \%$ were female; Evlice et al. (14) found that $66 \%$ of neurological patients were men and $34 \%$ were women. In our study, however, $46(51.1 \%)$ of the participants were male and $44(48.85 \%)$ were female. We observed no statistical difference between genders for cerebrovascular disease, epilepsy, and Parkinson's disease patients. Although dementia was more prevalent among women, no statistically significant difference was detected.

There are several studies in existing literature that analyze the correlation between frailty and disability, with one study demonstrating a notable correlation between frailty and disability in farmers over 65 years of age who live in rural areas (15). It has also been observed that frailty and disability rates are higher in older adults with anorexia of aging than in those without anorexia of aging (16).

Studies have also shown that frailty is an independent risk factor for injury, complications, and mortality among surgical patients: Pre-operational frailty assessments have predicted complications and mortality following cardiac and abdominal operation (17-19), while frailty has also been associated with higher mortality in lung and kidney transplant candidates and during the liver transplant waiting period (20-22). In addition, frailty has been shown to be a strong prognostic factor for mortality in elderly patients admitted for acute coronary syndrome and is associated with lower survival rates in colorectal carcinoma patients $(23,24)$.

In Turkey, documented severe disability is one criterion for receiving social support. Severe disability in patients ("fully dependent disabled" persons) is presented to a committee of physicians, who provide an opinion on disability status, with the possibility of different physicians having diverging opinions. We observed that patients with a frailty scale score $>8$ were more frequently certified as severely disabled, in line with Balthazard disability percentage assessments. This study also found 
strong correlation between EFS scores and Balthazard disability percentages and a correlation between physicians' opinion of severe disability status and EFS index scores. Since the EFS is an easy and fast scale that can be applied by the nurse working with the physician in outpatient clinics, it may ease physicians' decision making process for severe disability.

To date, no studies have used the EFS to predict how a patient admitted to a medical board for disability status approval will be assessed. As the first study in the field to do so, this research study is valuable. A limitation of this study was that only one month of medical board data was analyzed. More valuable results could be obtained from long-term

\section{REFERENCES}

1. Regulation on Disability Assessment for Adults No. 30692 dated February 20, 2019. T. C. Official Gazette, Number: 30692. [Internet] Available from: https://www.resmigazete.gov. tr/eskiler/2019/02/20190220-2.htm. Accessed: 20.02.2019(in Turkish)

2. Organization WH, World report on disability 2011, World Health Organization 2011. [Internet] Available from: https://apps.who.int/iris/handle/10665/44575. Accessed: 20.02.2019

3. Devlet İstatistik Enstitüsü (DiE). Türkiye Özürlüler Araştırması 2002. Ankara: 2004

4. Clegg A, Young J, Iliffe S, Rikkert MO, Rockwood K. Frailty in elderly people. The lancet 2013;381(9868):752-62. (PMID: 23395245)

5. Fried LP, Tangen CM, Walston J, et al. Frailty in older adults: evidence for a phenotype. The Journals of Gerontology Series A: Biological Sciences and Medical Sciences 2001;56(3):M146-M57. (PMID: 11253156).

6. Eeles EM, White SV, O'Mahony SM, Bayer AJ, Hubbard RE. The impact of frailty and delirium on mortality in older inpatients. Age Ageing 2012;41(3):412-6. (PMID: 22391613)

7. Collard RM, Boter H, Schoevers RA, Oude Voshaar RC. Prevalence of frailty in community-dwelling data analysis. We consider the strength of our research to be evident in its power analysis. Another important issue is that we conducted our study on patients who applied to the neurology outpatient clinic for evaluation by the health board. Therefore, our results are acceptable for neurology cases and cannot be generalized for all patients applying for health board evaluation.

In conclusion, we believe that the EFS, in combination with the Balthazard disability percentage assessment, could be a practical and rational method of assessing degree of disability and predicting severe disability status for patients whose disability status is being evaluated by a medical board.

older persons: a systematic review. J Am Geriatr Soc 2012;60(8):1487-92. (PMID: 22881367).

8. Nguyen $T$, Cumming R, Hilmer S. A review of frailty in developing countries. J Nutr Health Aging 2015;19(9):941-6. (PMID: 26482697)

9. Eyigor S, Kutsal Y, Duran E, et al. Frailty prevalence and related factors in the older adult-FrailTURK Project. Age 2015;37(3):50. (PMID: 25948502)

10. Rolfson DB, Majumdar SR, Tsuyuki RT, Tahir A, Rockwood K. Validity and reliability of the Edmonton Frail Scale. Age Ageing 2006;35(5):526-9. (PMID: 16757522)

11. Aygör HE, Fadıloğlu Ç, Şahin S, Aykar FŞ, Akçiçek F. Validation of Edmonton Frail Scale into elderly Turkish population. Archives of Gerontology and Geriatrics. 2018;76:133-7.

12. Cabalar M, Tatlidede AD, Yazar T, Guveli B, Yayla V. Evaluation of the neurological disability rates in medical commission. Medical Journal of Bakırkoy 2011;7(4):142-6.(in Turkish)(DOI: 10.5350/ BTDMJB201107404)

13. Benli AR, Cortuk M, Inci H, Benli NC. Evaluation of Causes Application on Medical Board. Konuralp Medical Journal 2016;8(3):167-72.(in Turkish) (DOI:10.18521/KTD.280035) 
14. Evlice A, Demir T, Aslan K, et al. Disability at Neurological Diseases. Cukurova Medical Journal 2014;39(3):566-71.(in Turkish)( DOI:10.17826 / CUTF.78721)

15. Choi Y-S, Kim M-J, Lee G-Y, et al. The association between frailty and disability among the elderly in rural areas of Korea. Int J Environ Res Public Health 2019;16(14):2481. (PMID: 31336809)

16. Tsutsumimoto K, Doi T, Makizako $H$, et al. Agingrelated anorexia and its association with disability and frailty. Journal of cachexia, sarcopenia and muscle 2018;9(5):834-43. (PMID: 30109778)

17. Dasgupta $M$, Rolfson DB, Stolee $P$, Borrie MJ, Speechley M. Frailty is associated with postoperative complications in older adults with medical problems. Arch Gerontol Geriatr 2009;48(1):78-83. (PMID: 18068828)

18. Tan K-Y, Kawamura YJ, Tokomitsu A, Tang T. Assessment for frailty is useful for predicting morbidity in elderly patients undergoing colorectal cancer resection whose comorbidities are already optimized. The American journal of surgery 2012;204(2):139-43. (PMID: 22178483)

19. Sündermann $S$, Dademasch $A$, Praetorius J, et al. Comprehensive assessment of frailty for elderly high-risk patients undergoing cardiac surgery. Eur J Cardiothorac Surg 2011;39(1):33-7. (PMID: 20627611)

20. McAdams-DeMarco M, Law A, King E, et al. Frailty and mortality in kidney transplant recipients. Am J Transplant 2015;15(1):149-54. (PMID: 25359393)

21. Singer JP, Diamond JM, Gries CJ, et al. Frailty phenotypes, disability, and outcomes in adult candidates for lung transplantation. Am J Respir Crit Care Med 2015;192(11):1325-34. (PMID: 26258797)

22. Lai JC, Feng S, Terrault NA, Lizaola B, Hayssen $\mathrm{H}$, Covinsky K. Frailty predicts waitlist mortality in liver transplant candidates. Am J Transplant 2014;14(8):1870-9. (PMID: 24935609)

23. Blanco $S$, Ferrières $J$, Bongard $V$, et al. Prognosis impact of frailty assessed by the Edmonton Frail Scale in the setting of acute coronary syndrome in the elderly. Can J Cardiol 2017;33(7):933-9. (PMID: 28668143)

24. Meyers BM, Al-Shamsi HO, Rask S, et al. Utility of the Edmonton Frail Scale in identifying frail elderly patients during treatment of colorectal cancer. J Gastrointest Oncol 2017;8(1):32-38 (PMID: 28280606) 